Lau, Stephan ; Petković, Bojana; Di Rienzo, Luca; Haueisen, Jens:

Optimizing a magnetic sensor vest for cardiac source imaging

Zuerst erschienen in: $\quad$ Biomedical Engineering = Biomedizinische Technik. - Berlin [u.a.] : de Gruyter. - 57 (2012), Suppl. 1, Track-E, p. 1016.

Erstveröffentlichung: 2012-08-30

ISSN (online): $\quad$ 1862-278X

ISSN (print): 0013-5585

DOI: $\quad 10.1515 / \mathrm{bmt}-2012-4163$

[Zuletzt gesehen: 2019-08-12]

„Im Rahmen der hochschulweiten Open-Access-Strategie für die Zweitveröffentlichung identifiziert durch die Universitätsbibliothek IImenau. “

"Within the academic Open Access Strategy identified for deposition by IImenau University Library."

„Dieser Beitrag ist mit Zustimmung des Rechteinhabers aufgrund einer (DFGgeförderten) Allianz- bzw. Nationallizenz frei zugänglich."

"This publication is with permission of the rights owner freely accessible due to an Alliance licence and a national licence (funded by the DFG, German

DFG

Research Foundation) respectively." 


\title{
Optimizing a magnetic sensor vest for cardiac source imaging
}

\author{
S. Lau ${ }^{1,2,4}$, B. Petkovic ${ }^{1}$, L. Di Rienzo ${ }^{3}$, J. Haueisen $^{1}$, \\ ${ }^{1}$ Institute of Biomedical Engineering and Informatics, Ilmenau Technical University, Ilmenau, Germany, \\ ${ }^{2}$ Biomagnetic Center, Department of Neurology, University Hospital Jena, Jena, Germany, \\ ${ }^{3}$ Politecnico di Milano, Dipartimento di Elettrotecnica, Milano, Italy, \\ ${ }^{4}$ Neuroengineering Lab., Dept. of Electrical and Electronic Eng., University of Melbourne, Parkville, Australia, \\ Email: jens.haueisen@tu-ilmenau.de
}

\section{Introduction}

Magnetocardiography non-invasively provides information about the electrical heart activity. New room temperature optically pumped magnetometers allow for placement of sensors around the body rather than enclosed in a cryostat. Therefore the question arises of where to optimally place the sensors.

\section{Methods}

We measured the magnetic field produced by the heart of a 72 year old cardiac patient. A boundary element model of the torso $(0.2 \mathrm{~S} / \mathrm{m})$ and lungs $(0.04 \mathrm{~S} / \mathrm{m})$ was created from a T1 weighted MRI. We modelled the cardiac sources with 13 dipoles arranged regularly around the left ventricle. The dipole orientations and amplitudes were fitted to the averaged PQRST interval of the MCG using a minimum norm approach and L curve regularization. We optimized the positions and orientations of a set of sensors with particle swarm optimization (PSO) with respect to the condition number $(\mathrm{CN})$ and the Skeel $\mathrm{CN}$ of the leadfield matrix. Because the solution is non-unique, we sampled the solution space of optimized sensor setups by optimizing repeatedly with random initialization and clustering the sensor positions to elicit generalizable patterns.

\section{Results}

The results indicate that sensors on the back of the torso are capturing relevant information. The optimized sensor distribution is non-uniform and denser at the frontal centre of the torso. The Skeel CN produces denser clusters, indicating more specific sensor placement, with better reflection of the heart's anatomy and excitation patterns, e.g. through the resemblance of the Wilson lead line. The smallest distance between optimized neighbouring sensors is approximately 4$5 \mathrm{~cm}$.

\section{Conclusion}

We conclude that a customized optimal field sampling on the whole torso surface can be derived using a representative volume conductor and source model. The vest concept is practical for clinical diagnostics in cardiology and for longterm monitoring such as a 24 hour MCG and might facilitate the definition of a robust standard for magnetic field imaging. 